\title{
A Concepção de Ensino Médio e de Currículo Expressa na Proposta de São Paulo
}

\author{
Dirce Djanira Pacheco e Zan*
}

\begin{abstract}
Resumo
Recentemente a Secretaria de Educação do Estado de São Paulo promoveu mudanças no currículo para o Ensino Médio das escolas da rede pública. Esse processo teve início no ano de $2008 \mathrm{com}$ a publicação dos primeiros documentos voltados para os ensinos Fundamental (II Ciclo) e Médio. Neste texto apresento - a partir de retomada histórica do debate acerca da identidade do Ensino Médio no país e dos documentos curriculares do governo federal divulgados desde os anos de 1990 - uma análise inicial dos documentos curriculares de São Paulo no que se refere à concepção deste nível de ensino e de currículo focando, em especial, as disciplinas de Ciências Humanas.
\end{abstract}

Palavras-chave: currículo, Ensino Médio, Estado de São Paulo.

\section{High School and curriculum conceptions in the official document of São Paulo State}

\begin{abstract}
Recently the Department of Education of São Paulo promoted changes in the curriculum for high school public level. This process began in 2008 with publication of the first documents to basic education (period II) and high school. This paper point out - from a historical perspective about the discussion about the school identity in the country and the federal government curriculum documents published since 1990's - an initial analysis of the curriculum documents of São Paulo State, focusing this scholar level, particularly, the disciplines of Humanities.

Key-words: curriculum, high school, São Paulo State.
\end{abstract}

Durante os anos de 1980 o país viveu ampla mobilização social em território nacional na luta pela democratização e a ampliação de direitos sociais dos brasileiros. A década se encerrou com a aprovação de uma nova Constituição Federal (1988), que selou o ciclo de lutas sociais e políticas de resistência ao regime ditatorial-militar iniciado em 1964. No texto constitucional aprovado, no capítulo referente à Educação, dentre outras novidades, é explicitado o reconhecimento do Ensino Médio como direito de todo cidadão brasileiro.

Alguns anos depois, na LDB (Lei de Diretrizes e Bases da Educação) de 1996, este direito foi reafirmado. O Ensino Médio passou a ser compreendido como etapa final da Educação Básica, implicando uma expansão dos anos de escolaridade desejáveis para todo cidadão. É importante ressaltar que a ampliação da Educação Básica é uma mudança significativa que, até certo ponto, reflete também a luta histórica de setores da sociedade brasileira pela sua entrada e permanência na escola até níveis mais elevados de ensino.

Mas a conquista do direito ao Ensino Médio não se deu de forma consensual. $O$ governo brasileiro levou certo tempo para assumilo, o que, de certo modo, aponta para possíveis tensões existentes, interna ou externamente ao governo, que retardou a incorporação deste como direito dos brasileiros. Exemplo de possíveis dificuldades pode ser percebido quando da participação do Brasil em seminário promovido pela UNICEF (Fundo das Nações Unidas para Infância) na cidade de Buenos Aires em setembro de 2008. Naquele evento o governo brasileiro foi cobrado para adotar o Ensino Médio como etapa final de escolarização obrigatória no país. Frente à pressão de lideranças políticas, a secretária de Educação Básica do MEC, profa. Maria do Pilar Lacerda, manifestou-se da seguinte forma: "Não existe mais possibilidade de inserção no mercado de trabalho sem o ensino médio. Isso força essa discussão e não podemos fugir dela. Mas será um tema polêmico." (Disponível em http//eeducador.com, acessado em 20/02/2009).

Mas no que consiste o Ensino Médio no Brasil? Segundo a legislação vigente esse nível de ensino tem como finalidades o aprofundamento dos conhecimentos adquiridos no Ensino Fundamental, a possibilidade de articulação entre os conhecimentos teóricos e práticos de cada uma das disciplinas, o aprimoramento do educando como pessoa humana e a preparação básica para o trabalho. Pode-se, até certo ponto, afirmar que a LDB de 1996 definiu o Ensino Médio como etapa final da Educação Básica, cujo objetivo maior seria a formação geral dos estudantes.

Durante os últimos anos, foram elaborados e divulgados diferentes documentos curriculares e em 2006, sob a orientação do governo Lula, o MEC novamente se manifestou lançando as Orientações Curriculares Nacionais para o Ensino Médio. Algo que era cobrado desde

\footnotetext{
* Endereço eletrônico: dircezan@ yahoo.com.br
} 
o início do primeiro mandato do então presidente. Em artigo publicado no ano de 2004, Lopes (2004) posiciona-se veemente neste sentido. A autora reconhece as dificuldades enfrentadas pelo governo em desmontar dispositivos de regulação das práticas curriculares estabelecidas em oito anos (p. 109) do governo anterior, mas cobra a necessidade de nova orientação da política educacional de forma mais ampla.

É possível notarmos que o olhar para o Ensino Médio vem se modificando nas últimas décadas e que essa mudança pode ser entendida como ressonância no âmbito do Estado das lutas e reivindicações de diferentes setores. Se por um lado existe a demanda por ampliação da escolarização enquanto direito social, por outro surgem mudanças no processo produtivo que apontam para a necessidade de um trabalhador mais flexível e com habilidades e competências até então pouco exigidas.

A expansão do Ensino Médio, associada à sua reorganização curricular, passou a ser vista desde a última década, como fundamental para a integração e a "sustentabilidade" do país no mercado global. Em parte esse argumento é reforçado por documentos de organismos internacionais voltados para a política educacional na América Latina e que, até certo ponto, inspiraram os documentos curriculares brasileiros.

A preocupação em oferecer um Ensino Médio que também promova a adaptação do aluno às novas formas de organização do trabalho está presente nos documentos curriculares nacionais desde os anos de 1990. O documento de $1998^{1}$, por exemplo, expressa a orientação política fundamentada nos princípios do neoliberalismo e a preocupação com a constituição de um modelo de Ensino Médio que proporcione a adaptação dos jovens às atuais condições de trabalho. Segundo o referido texto

...nas condiçães contemporâneas de
produção de bens, serviços e
conhecimentos, a preparação de recursos
humanos para um desenvolvimento
sustentável supõe desenvolver capacidade
de assimilar mudanças tecnológicas e
adaptar-se a novas formas de
organização do trabalho... (p. 18).

Nesse mesmo período, criou-se no país o nível da Educação Profissional, que ocorreria concomitante ou posteriormente ao Ensino Médio e que teria por objetivo maior a profissionalização, podendo ser oferecido em instituições de ensino regular ou por diferentes modalidades de educação continuada tanto em instituições especializadas como no próprio local de trabalho (LDB 1996, art. 40).

Cerca de uma década depois, o debate sobre a finalidade formativa do Ensino Médio está posta novamente. Em julho de 2008, o governo federal divulgou documento intitulado Reestruturação e Expansão do Ensino Médio no Brasil que objetiva viabilizar a concretização de um Ensino Médio integrado. Busca-se no texto explicitar a identidade deste nível de ensino, ou seja, ...configurar uma identidade do ensino médio, como etapa da educação básica, construída com base em uma concepção curricular unitária, com diversidade de formas, cujo princípio é a unidade entre trabalho, cultura, ciência e tecnologia (BRASIL, 2008, p. 8).

É evidente, nos últimos anos, a ampliação do interesse por parte de governos, seja federal ou estadual, para com o nível médio de ensino. Os jovens passaram a ser uma preocupação recorrente nas políticas públicas mais recentes. Podemos afirmar que desde a LDB de 1996 iniciou-se uma corrida com a finalidade de ampliação e até mesmo universalização desse nível de ensino. Junto a esse processo de expansão, novas diretrizes e orientações curriculares são divulgadas, reafirmando o que Arroyo (1999) apontava em outro momento, ou seja, o sentido estratégico de se rever currículos e centrar neles o foco em tempos de mudanças educacionais.

Neste contexto de retomada do debate acerca da identidade do Ensino Médio e da necessária articulação entre formação para o trabalho e formação geral, o estado de São Paulo dá início a uma nova empreitada na formulação de documentos curriculares que passaram a nortear $\mathrm{o}$ trabalho nas escolas públicas paulistas.

\section{O Movimento em São Paulo}

O ano letivo de 2008 iniciou com a chegada nas escolas estaduais do que se tornou conhecido como o Jornalzinho do Estado. Sob o título São Paulo faz Escola, foi distribuído nas escolas estaduais um Jornal impresso que trazia notícias, curiosidades e sugestões de atividades ${ }^{2}$ a serem desenvolvidas pelos professores de cada uma das disciplinas do II ciclo do Ensino Fundamental ( $5^{\mathrm{a}}$ a $8^{\mathrm{a}}$ séries) e do Ensino Médio durante os 42 primeiros dias de trabalho.

O Jornal, escrito em uma linguagem direta e focada no aluno, apresenta o conteúdo das diferentes disciplinas, distribuído pela quantidade de aulas de cada uma e destinado às várias séries. Com temas atuais e partindo de questões contemporâneas, estabelece, nos textos curtos que apresenta, uma relação com conceitos e temas que 
deverão ser ampliados pelo professor em sala de aula. Sugere ainda atividades a serem realizadas pelos alunos individual ou coletivamente. A opção pela centralidade do texto como foco do trabalho em sala de aula é enfatizada durante o material. Segundo a Revista do Professor, distribuída na rede posteriormente, o Jornal foi construído levando em consideração os resultados do SARESP $^{3}$ (Sistema de Avaliação de Rendimento Escolar do Estado de São Paulo) de 2005.

Para o Ensino Médio foram produzidas cinco revistas contemplando as disciplinas: Língua Portuguesa; Matemática; Física/Química/Biologia;

Geografia/História/Filosofia e Arte/Língua Estrangeira Moderna/Educação Física. Os textos nelas apresentados são dirigidos aos professores de cada uma das disciplinas e em cada uma das três séries do Ensino Médio, com o objetivo de detalhar as possibilidades de "aplicação" e de avaliação das atividades propostas para o aluno no Jornal (São Paulo, 2008, p. 11). Além desse material impresso, Jornal e Revista para o professor, a equipe gestora e os professores receberam orientações por meio de vídeos tutoriais que apresentavam princípios da organização do material.

Nessa estratégia do governo paulista é possível vislumbrarmos uma concepção de divisão do trabalho pedagógico, já analisada por outros autores e presente em diferentes momentos de nossa história, ou seja, cabe à burocracia estatal pensar e planejar o trabalho que será "aplicado" pelo professor em sala de aula ${ }^{4}$. De certo modo, essa concepção curricular, expressa no material divulgado pela Secretaria de Educação de São Paulo, reafirma o que Hypólito (1991) sinaliza ao analisar o contexto das reformas curriculares do final do século XX: a opção por um modelo técnico-burocrático, caracterizado pela redução da autonomia do professor em relação ao ensino e à organização da escola.

São anunciadas, nessas Revistas, as habilidades e competências que necessitam ser recuperadas ou consolidadas pelos alunos em cada uma das disciplinas durante o período de 42 dias. São habilidades voltadas principalmente para o raciocínio lógico-matemático, além de leitura e escrita. A Revista do Professor reconhece o grave problema enfrentado nos ensinos Fundamental e Médio do estado que conta com a presença de alunos que ainda não dominam a base alfabética da escrita - entendida no referido documento como a capacidade de compreender como se representa a escrita no sistema alfabético, realizando uma ação de ordem cognitiva - $e$ que, portanto, não conseguirão de forma plena acompanhar as ações propostas. (2008, p. 17) O documento define ainda como meta para o final do ano de 2008 a alfabetização de todos esses alunos.

No caso específico das disciplinas de Ciências Humanas, revelou-se naquele momento uma preocupação em iniciar o trabalho em cada uma delas a partir da reflexão acerca das suas respectivas "utilidades" na formação do jovem estudante. Por que estudar História? Mas, afinal, por que e para que estudar História? E o que você tem com isso? São essas, por exemplo, algumas das indagações iniciais do texto referente à disciplina de História. Na Revista do Professor, há orientações para que o ensino dessa disciplina suscite em classe discussões sobre as questões, procurando aprofundar a reflexão e superar respostas superficiais e repetitivas. O material propõe que o aluno entre em contato com uma História que representa a própria identidade das formações sociais (Jornal do Aluno, p. 19). A disciplina é considerada importante para a formação de cidadãos críticos por promover a percepção da identidade social e da necessidade de preservação da memória individual e coletiva.

$\mathrm{Na}$ Revista das disciplinas de Ciências Humanas, ficam mais claras as habilidades que se espera que os alunos adquiram. Elas estão divididas entre aquelas voltadas para a leitura e produção de texto e as relacionadas especificamente com os conhecimentos disciplinares.

Para a disciplina de Geografia, destaca-se a importância de garantir, ao longo da Educação Básica, que o aluno saiba interpretar e fazer uso de conhecimentos geográficos tais como o da cartografia. Diz a Revista do Professor:

considerando a leitura de mapas $e$ gráficos, instrumento indispensável para a compreensão do espaço em todas as suas dimensões, as atividades deste caderno foram elaboradas retomando, inicialmente, os referenciais de orientação e localização, para posteriormente se trabalhar com as formas de representação do espaço em sua dimensão gráfica e cartográfica. Os conteúdos aqui trabalhados estão a serviço da habilidade e, portanto, também devem ser recolocados de forma a fazer com que os alunos retomem conceitos significativos para a sua formação geral (SÃO PAULO, 2008, p. 18).

Tecendo críticas a um ensino de Geografia centrado na descrição de paisagens ou 
no manuseio de uma cartografia obsoleta que não leva em consideração os novos recursos tecnológicos, representativos de uma Geografia descritiva e mnemônica (p. 29), propõem-se ensinar aos alunos os procedimentos que lhes possibilite tirar informações e sensações dessas novas expressões de comunicação resultantes da junção dos diversos saberes e da disponibilidade de novas formas de expressão do conhecimento. (p. 29) Tal orientação para o ensino de Geografia visa não apenas a garantia da aprendizagem de habilidades importantes para a disciplina como também contribuir para desenvolver habilidades de síntese e ordenamento de informações além de ampliar a capacidade do estudante de argumentar e aprimorar o seu senso crítico (p. 29).

Ao final das orientações, enfatiza-se a preocupação dos autores em garantir a oportunidade aos alunos do Ensino Médio de reverem conteúdos conceituais, procedimentais e atitudinais indispensáveis à sua formação.

É possível notar aqui uma retomada do discurso presente nos primeiros documentos curriculares lançados pelo governo federal nos anos de 1990. Segundo documento introdutório dos Parâmetros Curriculares Nacionais do Ensino Fundamental (BRASIL, 1997), os conteúdos conceituais referem-se à construção ativa das capacidades intelectuais dos indivíduos para operar com símbolos, idéias, imagens e representações que permitem organizar a realidade (p. 74), enquanto que os conteúdos procedimentais referem-se, de certo modo, à capacidade de continuar aprendendo, de buscar informações e de investigar. Nesse sentido, está implícito que, ao se ensinar procedimentos, também se ensina um certo modo de pensar e produzir conhecimento. Os conteúdos atitudinais permeiam todo o conhecimento escolar (p. 76) e se referem às atitudes aprendidas pelos alunos durante sua vida escolar, isto é, atitudes em relação ao conhecimento, ao professor, aos colegas, às disciplinas e à sociedade.

Essa forma de conceber os conteúdos está fortemente marcada pela teoria cognitivista, que, como já analisado por diferentes autores, fundamentou os documentos nacionais naquele momento, principalmente sob a influência do pensamento de César Coll. Para Moreira (1997), por exemplo, a perspectiva psicológica defendida por esse autor manifesta-se de forma contundente nos documentos de 1990. Nessa perspectiva, qualidade de ensino é compreendida de forma restrita às necessidade $e$ interesses individualmente considerados (p. 96). Há, segundo Moreira (1997), uma desconsideração do caráter político inerente a essa discussão. Da mesma forma, a análise dos documentos paulistas nos remete a essa compreensão individualizada da aprendizagem e da qualidade de ensino.

De uma forma ampliada foi publicada, alguns meses depois, a Proposta Curricular do Estado de São Paulo com orientações curriculares explícitas para cada uma das disciplinas. É importante ressaltar a opção do Estado em publicar cadernos organizados por disciplinas e não pelas três grandes áreas definidas desde os primeiros documentos curriculares nacionais voltados para o Ensino Médio e divulgados pelo MEC, ou seja: Linguagem, Código e suas tecnologias; Ciências da Natureza, Matemática e suas tecnológicas e Ciências Humanas e suas tecnologias. Mas, diferentemente dos documentos federais, parece haver uma estratégia de valorização dos conteúdos, pois, apesar de centrar-se no desenvolvimento de competências e habilidades, enfatiza-se a necessária garantia de conteúdos disciplinares que serão definidos nos documentos específicos das disciplinas.

$\mathrm{O}$ documento de apresentação da $\operatorname{proposta}^{5}$ afirma que esta é resultado de conhecimentos e práticas acumuladas, de síntese, revisão e recuperação de documentos já publicados sobre currículo no Ensino Médio, bem como de diagnósticos feitos acerca da condição das escolas. Afirma que a Secretaria de Educação do Estado atuará a partir de amplo levantamento do acervo documental e técnico pedagógico existente e consultará escolas e professores, visando a identificar, sistematizar e divulgar "boas práticas existentes nas escolas". De acordo com o texto, essa proposta visa a proporcionar a todos os estudantes da rede pública estadual paulista uma base comum de conhecimentos e competências para que as escolas funcionem como rede, e elege como prioridade desta reforma a garantia da competência da leitura e escrita na formação desses alunos.

A partir de então, é possível observarmos algumas concepções que são elucidadas no documento curricular introdutório. A escola é definida como espaço de cultura e de articulação de competências e conteúdos disciplinares. Nesse sentido, o documento anuncia uma compreensão no mínimo ambígua ao afirmar que é possível e desejável um currículo padrão para toda a rede, uma vez que "alunos e professores são únicos". Dessa forma, explicita uma noção a-crítica acerca da cultura ao não considerar os conflitos e interesses distintos que permeiam os processos culturais e a diversidade cultural que se manifesta nas diferentes regiões do estado de São Paulo.

$\mathrm{O}$ adolescente, aluno por excelência dessa etapa da Educação Básica, é entendido como 
aquele que deixou de ser criança e se prepara para a vida adulta, ou seja, um sujeito em transformação. Ao assumir a adolescência nessa perspectiva, o documento desconsidera o adolescente enquanto sujeito no processo educacional e social. Segundo Calligaris (2000), essa concepção do adolescente tem criado uma situação problemática para os jovens na contemporaneidade, pois, ao mesmo tempo em que são reconhecidos como aqueles que necessitam ainda da tutela dos adultos, eles são instigados a se tornarem indivíduos independentes. Isso torna ainda mais penoso o hiato que a adolescência instaura entre aparente maturação dos corpos e ingresso na vida adulta. Apesar da maturação dos corpos, a autonomia reverenciada, idealizada por todos como valor supremo, é reprimida, deixada para mais tarde (p. 17).

Como parte ainda do diagnóstico relatado no documento, discorre-se sobre uma precocidade da adolescência articulada com uma inserção tardia no mercado de trabalho. Neste momento não há nenhuma discussão mais aprofundada acerca da afirmação feita, ou seja, pesquisas na área do trabalho têm apontado para a expressiva presença dos jovens entre os desempregados no país. Segundo dados do Instituto de Pesquisa Econômica Aplicada (IPEA), em 2005, época próxima à produção e divulgação da referida proposta, o desemprego da população entre $15 \mathrm{e}$ 24 anos era 3,5 vezes maior do que o medido entre os trabalhadores que haviam ultrapassado essa faixa etária ${ }^{6}$. Nesse sentido, torna-se superficial a afirmação acerca da tardia inserção no mercado de trabalho, pois ela parece resultar muito mais de questões estruturais vividas pelo país naquele momento do que de uma opção dos jovens estudantes. Além disso, pesquisadores como Dayrell, têm apontado em seus estudos que, para muitos jovens brasileiros, trabalhar é condição imprescindível para viver sua condição juvenil.

O Governo do Estado apresenta, a partir desta proposta curricular, sua concepção acerca da educação que julga necessária para o contexto atual, ou seja, uma educação geral, articuladora, que transite entre o local e o mundial (São Paulo, 2008). Construir identidade, agir com autonomia $e$ em relação com o outro, $e$ incorporar a diversidade são as bases para a construção de valores de pertencimento e responsabilidade, essenciais para a inserção cidadã nas dimensões sociais e produtivas. Preparar indivíduos para manter o equilíbrio da produção cultural, num tempo em que a duração se caracteriza não pela permanência, mas pela constante mudança - quando o inusitado, o incerto $e$ o urgente constituem a regra e não a exceção -, é mais um desafio contemporâneo para a educação escolar (p. 6).

O documento defende princípios que norteiem um currículo comprometido em garantir uma formação que atenda às demandas e modificações do mundo contemporâneo. Aponta para a necessidade de se compreender a escola como espaço de aprendizagem e no qual a convivência passa a ser encarada de forma intencional, ou seja, como situação de aprendizagem. Fundamentando-se na LDB 9394/96, o texto afirma que foi a partir da referida lei que se passou a conceber a aprendizagem enquanto direito (p. 9).

O currículo é definido como espaço de cultura. Currículo, diz o texto oficial, é a expressão de tudo o que existe na cultura científica, artística e humanista, transposto para uma situação de ensino e aprendizagem (p. 8). Essa afirmação desconsidera o caráter seletivo do currículo, ignora a ampla produção acadêmica que tem se intensificado desde os anos de 1990 no país e que apresenta o currículo como espaço de luta e embates sociais, culturais e políticos. Ao defender que se parta das competências como referência, isto é, ao aceitar o desafio de promover os conhecimentos próprios de cada disciplina articuladamente às competências e habilidades do aluno... (p. 8), assume-as como aquelas que caracterizam os modos de ser, raciocinar $e$ interagir que podem ser depreendidos das ações e das tomadas de decisão em contextos de problemas, tarefas ou atividades... (p. 9).

Essa opção do currículo por competência está relacionada, segundo o próprio documento, com o compromisso por uma escola democrática. No momento em que se conclui o processo de universalização do Ensino Fundamental e se incorpora toda a heterogeneidade que caracteriza $o$ povo brasileiro - afirma o documento - $a$ escola, para ser democrática, tem de ser igualmente acessivel a todos, diversa no tratamento de cada um e unitária nos resultados. (p. 10). Para a construção da unidade, é portanto necessário se enfatizar o que é indispensável: que todos tenham aprendido no final do processo, visando a ...garantir igualdade de oportunidades, diversidade de tratamento e unidade de resultados... (p. 10). A justificativa para um currículo centrado nas competências aparece posteriormente no documento ao afirmar-se que as competências são mais gerais e constantes, $e$ os conteúdos, mais específicos e variáveis... (p. 13). 
As competências adotadas pela proposta curricular são definidas a partir do referencial teórico do Exame Nacional do Ensino Médio (ENEM): dominar a norma culta da Língua Portuguesa e fazer uso da Linguagem Matemática; construir e aplicar conceitos das várias áreas do conhecimento para a compreensão de fenômenos naturais, de processos histórico-geográficos, da produção tecnológica e das manifestações artísticas; selecionar, organizar, relacionar, interpretar dados e informações representadas de diferentes formas, para tomar decisões e enfrentar situações-problema; relacionar informações, representadas em diferentes formas, e conhecimentos disponíveis em situações concretas, para construir argumentação consistente; e recorrer aos conhecimentos desenvolvidos na escola para elaborar propostas e intervenção solidária na realidade, respeitando os valores humanos e considerando a diversidade sociocultural - todas elas convergindo para a competência maior da leitura e escrita, que deve ser assumida como objetivo da formação no Ensino Médio, pois é na adolescência que a linguagem adquire essa qualidade de instrumento para compreender e agir sobre o mundo real (p. 11) (grifos da autora), afirma o texto oficial.

A proposta compreende a leitura como a capacidade do estudante de interpretar, atribuir sentido ou significado; compreender, assimilar experiências ou conteúdos disciplinares; antecipar ação para intervir no fenômeno e resolver problemas dele decorrentes; sintetizar a capacidade de escutar, supor, informar-se, relacionar, comparar, etc; e descrever, compreender, argumentar a respeito de um fenômeno. Da mesma forma a escrita tem seu sentido ampliado e é assim definida pelo documento: assumir autoria individual ou coletiva; expressar sua construção ou reconstrução com sentido, aluno por aluno; dominar os muitos formatos que a solução do problema comporta; dominar os códigos que expressam a defesa ou reconstrução de argumentos, além de construir um plano para essa intervenção.

Diferentes autores têm se posicionado criticamente acerca do currículo por competências, que ganha destaque desde os primeiros documentos brasileiros dos anos de 1990. Segundo Zibas (2005), as primeiras críticas a essa concepção "apontaram a origem do conceito no modelo de competências desenvolvido na área empresarial para a seleção e treinamento de trabalhadores (p. 27). Posteriormente, o aporte psicológico da pedagogia das competências foi criticado por visar à construção do novo profissionalismo" (p. 28), ou seja, é um modelo que enfatiza os aspectos subjetivos dos alunos e que, de certo modo, está em sintonia com as mudanças do processo produtivo atual, que visa a uma melhor adequação do trabalhador às novas formas de organização do mundo do trabalho.

A proposta curricular visa a atingir também a gestão da escola. Chama à responsabilidade os gestores - considerados no documento de apresentação da proposta como os responsáveis pela formação continuada dos professores - para proporcionarem o desenvolvimento das capacidades de leitura e escrita também nos professores, ou seja, criar oportunidades para que os docentes desenvolvam essas competências.

A proposta retoma, de certo modo, a orientação presente nos documentos de uma década atrás, ou seja, a necessidade de se garantir a relação entre o que se aprende na escola com a vida cotidiana dos estudantes. Defendendo que $s e$ a educação básica é para a vida, a quantidade e a qualidade do conhecimento têm de ser determinadas por sua relevância para a vida de hoje e do futuro, além dos limites da escola. (p. 13) Porém, como naqueles primeiros documentos, apresenta uma compreensão acrítica da vida contemporânea, há uma nítida intenção de que a escola instrumentalize seus alunos para se adaptarem a realidade atual sem levantar qualquer tipo de questionamento acerca desta realidade.

É no contexto do trabalho que se pretende efetivar a contextualização desta reforma curricular. Retomando os Parâmetros Curriculares Nacionais para o Ensino Médio e assumindo-os como também balisadores para o Ciclo II do Ensino Fundamental. O trabalho é assumido como tema e como valor na proposta aqui apresentada. Segundo o documento de apresentação da proposta, as Diretrizes Curriculares Nacionais para o Ensino Médio abriram a possibilidade para que os sistemas de ensino ou as escolas tenham ênfases curriculares diferentes, ...com autonomia para eleger as disciplinas específicas e suas respectivas cargas horárias dentro das 3 grandes áreas instituídas pelas DCN's, desde que garantida a presença das três áreas...(p. 19). No entendimento da Secretaria de Educação de São Paulo, isto permite que escolas de Ensino Médio articulem seu projeto pedagógico a cursos de educação profissional de nível técnico e/ou que possam oferecer disciplinas que depois serão aproveitadas no curso profissionalizante. Apontase, portanto, que o currículo do Ensino Médio seja definido com base em conteúdos disciplinares constituintes de competências básicas que sejam também pré-requisitos de formação profissional. 
Talvez este seja o caso, por exemplo, da ênfase na tecnologia.

A presença da tecnologia como norteador desta proposta é então compreendida como educação tecnológica básica e como fundamento necessário à compreensão do desenvolvimento científico e tecnológico da produção. Aponta-se para a necessidade de se garantir durante a Educação Básica a alfabetização tecnológica básica, ou seja, entender as tecnologias da história humana como elementos da cultura. Posteriormente, num processo de educação tecnológica básica, visa à preparação dos estudantes para viverem neste mundo tecnologizado.

Há a defesa da diversificação do Ensino Médio, que, até certo ponto, materializa-se na flexibilização do currículo e na ênfase cada vez maior em proporcionar uma formação profissionalizante dos jovens estudantes desse nível de ensino. Várias têm sido as iniciativas do Estado neste sentido ${ }^{7}$ que merecem ser estudadas e acompanhadas por pesquisadores da área.

Essa concepção de certo modo mostra-se inspirada em documentos de organismos internacionais divulgados no início dos anos 2000. Documento publicado pela UNESCO em $2002^{8}$ apontava para a necessidade de que os países latinos oferecessem a cada jovem entre 16 e 18 anos uma educação básica de 12 anos, além de diversificar a oferta do que é ali chamado de "Educação Secundária". Tal diversificação possibilitaria atender às necessidades de uma população estudantil muito exigente, segundo o referido documento, permitindo assim que cada um pudesse explorar seus interesses e aptidões visando a uma inserção positiva e criativa no mundo dos adultos. ... O mais importante (hoje) afirmam Caillods e Hutchinson - é dispor de uma força de trabalho formada competitiva e flexível (p. 24).

Desse modo se justifica, até certo ponto, a ênfase dos documentos curriculares dos últimos anos, na garantia do desenvolvimento de competências e habilidades. Segundo Caillods e Hutchinson (2002), as novas tecnologias transformaram profundamente a organização do trabalho e, portanto, são necessárias agora competências transversais, como capacidade de ser criativo, solucionar problemas concretos, tomar decisões de maneira autônoma, trabalhar em equipe e saber aprender... (p. 26).

No caso específico das Ciências Humanas, o documento de apresentação da proposta curricular paulista reconhece como disciplinas que compõem essa área as de História, Geografia, Filosofia, Sociologia e Psicologia, além de outras como Política, Antropologia e Economia. Enfatiza-se o caráter interdisciplinar da área e a importância da mesma no auxílio dos jovens para a compreensão de questões que os afetam, além de contribuir para as tomadas de decisões diante dos problemas que se apresentam no início do século XXI. Aparentemente poderíamos entender que há uma preocupação e se atribui papel relevante para esta área, mesmo em um currículo comprometido com a formação para o mercado de trabalho. Entretanto, ao analisarmos, por exemplo, o caso da disciplina de Sociologia, fica evidente a contradição no discurso expresso no documento. Vejamos o caso dessa disciplina no currículo paulista.

O retorno da Sociologia ao currículo do Ensino Médio no estado se deu a partir do ano de 2009. Apesar de resolução do Conselho Nacional de Educação (CNE) datada de 2006, que tornava as disciplinas de Filosofia e Sociologia obrigatórias no currículo do Ensino Médio, esta última não foi incorporada à matriz curricular das escolas paulistas naquele momento. Com a aprovação da Lei 11.684/2008 pelo MEC, que torna obrigatória a presença das duas disciplinas, o Governo de São Paulo anunciou a inserção da Sociologia a partir do ano letivo de 2009. No entanto, a forma como ela retorna ao currículo tem causado discussões e debates.

Segundo o jornal Folha de São Paulo ${ }^{9}$, a entrada da disciplina de Sociologia representaria a supressão de aulas de História no currículo do Ensino Médio. Em matéria intitulada Aluno de Escola Estadual terá 80 aulas de História a menos, a reportagem diz que o governo estadual afirma não ser possível ampliar a jornada diária de estudantes e professores do Ensino Médio, sendo assim, para acatar a lei federal que inclui a disciplina de Sociologia e amplia a carga horária da disciplina de Filosofia, a única saída foi reduzir aulas das disciplinas de História, Educação Física e Geografia no período diurno, além da disciplina de língua estrangeira (em geral, inglês ou espanhol) no período noturno. Tal opção do governo para inclusão da disciplina possivelmente provocou resistência de colegas no interior da escola, que viram suas disciplinas terem a carga horária reduzida ou assumiram, mesmo sem formação específica, as aulas de Sociologia como forma de não perderem aulas e terem seus salários reduzidos.

\section{Reações Iniciais}

Em matéria intitulada "Reforma Curricular em São Paulo: a contra-mão do progresso", disponível no site "professor 
temporario.wordpress.com", um grupo de professores se manifesta contrário à proposta curricular do estado, principalmente no que se refere ao que chamam de semi-profissionalização do Ensino Médio. Além disso, criticam a proposta por restringir o conteúdo a ser disponibilizado aos alunos paulistas, limitando-os ao conhecimento básico da leitura e dos fundamentos da Matemática.

Em maio de 2008, o Fórum da Graduação promovido pela ANPUH (Associação Nacional de História) - Seção São Paulo teve como objetivo discutir a proposta curricular da disciplina de História do Estado de São Paulo, implantada na rede pública paulista a partir do ano letivo de 2008. Nessa reunião, ocorrida na USP, estiveram presentes representante da Secretaria Estadual da Educação - professor Paulo Miceli, autor do documento de História - professores das Universidades paulistas, públicas e particulares, membros do GT (Grupo de Trabalho) de Ensino da referida Associação, do Conselho Consultivo e da Diretoria da Seção São Paulo da Anpuh, além de professores dos ensinos fundamental e médio.

Dessa reunião resultou uma moção publicada no site da entidade com o objetivo de registrar contradições e inconsistências relativas a esta Proposta Curricular de História. São destacadas principalmente a concepção de currículo implícita na proposta e o seu processo de implantação, que reduz o professor a mero executor de propostas elaboradas a priori, de maneira unidimensional, desconsiderando projetos em desenvolvimento nas escolas, bem como as discussões acumuladas nos últimos trinta anos, envolvendo pesquisas sobre a história das disciplinas escolares, saberes históricos escolares, culturas escolares e saberes docentes, dentre outras.

O documento aponta para a dubiedade do texto curricular, pois, apesar de nas proposições mais gerais e nos princípios da Proposta Curricular ser mencionada concepção curricular e educacional pautadas por uma perspectiva sóciohistórica, esta não é de fato incorporada. Pelo contrário, o conjunto de documentos apresentados, apesar de referir-se à autonomia, ao pensar crítico, como metas educacionais a serem colocadas em práticas por docentes $e$ discentes, acaba, ambiguamente, negando-os. A lógica que prevalece é a de um sistema interessado numa produtividade mensurável, politicamente controlada, por meio de procedimentos avaliativos padronizados e mecanicamente colocados em ação.

Outra reação organizada foi a da APEOESP (Associação de Professores do Ensino
Oficial de São Paulo), que, após reunião com pesquisadores, manifestou-se no Boletim intitulado "Proposta Curricular do Estado de São Paulo: uma análise crítica". Dentre as principais críticas estão a maneira como a proposta foi inserida na rede, ou seja, sem a necessária participação de todos os envolvidos direta ou indiretamente no processo educacional escolar; a desconsideração acerca da diversidade cultural do estado presente na proposta e a posição de "aplicador de currículo" que é atribuída aos professores da rede. $\mathrm{O}$ documento afirma que o currículo apresentado no documento é restrito e retira a autoria do trabalho didático e a autonomia docente. Nesse sentido, a entidade analisa que essa proposta está alinhada com as diretrizes sociais e econômicas do chamado capitalismo globalizado. E aponta que esta concepção social e econômica tem demonstrado não ser eficiente na resposta às necessidades da sociedade em relação ao trabalho, saúde, educação, lazer...

$\mathrm{Na}$ análise apresentada pela entidade há uma confluência no que tenho apresentado neste texto, ou seja, uma compreensão de que a proposta curricular paulista se aproxima das orientações curriculares difundidas pelos organismos internacionais a partir dos anos de 1990. Da forma como estão organizados, os Cadernos podem ser vinculados aos famosos guias didáticos expressamente orientados pelas políticas educacionais do Banco Mundial, afirma o Boletim.

O documento termina por conclamar os professores a se organizarem e posicionarem criticamente frente a esta proposta no momento do planejamento que se iniciava no ano de 2009. A forma como os professores têm se manifestado acerca destes documentos carece ainda de estudos.

\section{Algumas Considerações}

É possível observarmos uma aproximação do discurso curricular da proposta paulista com o presente nos documentos curriculares publicados nos anos de 1990, tendo como ênfase o objetivo de promover o desenvolvimento de competências e habilidades, principalmente aquelas voltadas para a leitura e escrita.

Apresenta-se uma concepção do professor como "aplicador da proposta". É também retomada uma noção de padronização da aprendizagem, desconsiderando tantas pesquisas que apontam para esta como uma atividade de apropriação do conhecimento que é cultural, histórica, social e singular.

Na busca de garantir a implementação da proposta curricular, há um envolvimento da 
equipe gestora que passa a ser estratégica no processo atual.

São necessários estudos que aprofundem a análise sobre os documentos apresentados pelo estudo, bem como aqueles que se voltem para o cotidiano escolar com o objetivo de analisar esse processo.

\section{Referências Bibliográficas}

BRASIL. Ministério da Educação. Reestruturação e Expansão do Ensino Médio no Brasil. Julho de 2008. Disponível em www.mec.gov.br

BRASIL. Secretaria de Educação Fundamental. Parâmetros Curriculares Nacionais: introdução aos parâmetros curriculares nacionais. Brasília: MEC/SEF, 1997.

CAILLODS, Françoise e HUTCHINSON, Francis. Aumentar a Participação na Educação Secundária na América Latina? Diversificação e Equidade, in BRASLAVSKY, Cecília (org.) Educação Secundária: mudança ou imutabilidade? Brasília: UNESCO, 2002.

CALligARIS, Contardo. A Adolescência. SP: PubliFolha, 2000.
FREITAS, Luiz Carlos de. Neotecnicismo e Formação de Professores, in ALVES, Nilda (org) Formação de Professores: pensar e fazer. SP: Ed. Cortez, 1992.

HYPÓLITO, Álvaro Moreira. Processo de Trabalho na Escola: algumas categorias para análise. Teoria \& Educação, n. 4. Porto Alegre: Pannonica Editora Ltda, 1991.

KUENZER, Acácia (org.) Ensino Médio: construindo uma proposta para os que vivem do trabalho. SP: Ed. Cortez, 2000.

LOPES, Alice Casimiro. Políticas Curriculares: continuidade ou mudança de rumos? Revista Brasileira de Educação, n. 26, mai/jun/jul 2004.

MOREIRA, Antônio Flávio. A Psicologia... e o Resto: o currículo segundo César Coll, in Cadernos de Pesquisa Carlos Chagas, n. 100, mar/1997.

SÃO PAULO. Governo do Estado de São Paulo. Revista São Paulo faz Escola: Edição Especial da Proposta Curricular. Disciplinas Geografia, História e Filosofia, 2008.

ZIBAS, Dagmar. A Reforma do Ensino Médios nos anos de 1990: o parto da montanha e as novas perspectivas, in Revista Brasileira de Educação, n. 28, jan/fev/mar/abr 2005. 


\section{Notas}

1 Parâmetros Curriculares Nacionais para o Ensino Médio (PCNEM).

2 Texto que compõe a apresentação escrita pela Coordenadora do Projeto, profa. Maria Inês Fini.

3 Sistema de Avaliação de Rendimento Escolar do Estado de São Paulo (SARESP) tem por objetivo avaliar o Ensino Básico nas escolas públicas do estado. Desde 1996 é aplicado anualmente.

4 Uma leitura importante sobre o tema é a do artigo Neotecnicismo e Formação de Professores de Luiz Carlos de Freitas, publicado no livro Formação de Professores: pensar e fazer organizado por Nilda Alves e editado pela Cortez em 1992.

5 SÃO PAULO. Proposta Curricular para Ensino Fundamental (Ciclo II) e Ensino Médio. Documento de Apresentação. 2008. Disponível em www.fazendoescola.sp.gov.br

6 www.ipea.gov.br

7 Quanto à diversificação do Ensino Médio, em conferência proferida pela profa. Maria Inês Fini coordenadora da proposta curricular do estado de São Paulo - no Seminário Os Desafios do Ensino Médio, ocorrido na Unicamp em 07 de novembro de 2008, se informou que o estado em parceria com o município de Indaiatuba, por exemplo, ofereceu naquele ano 2.600 vagas para estudantes matriculados no ensino médio estadual frequentarem gratuitamente um dos cursos técnicos oferecidos pela Fundação Indaiatubana de Educação e Cultura (Fiec).

8 BRASLAVSKY, Cecília (org.) Educação Secundária: mudança ou imutabilidade? Brasília: UNESCO, 2002.

9 Matéria publicada em 06 de dezembro de 2008 no Caderno Cotidiano.

\section{Sobre a autora:}

Dirce Djanira Pacheco e Zan: Docente do Programa de Pós Graduação em Educação da Faculdade de Educação- Unicamp. 